\title{
Simulating Buoyancy-Driven Airflow in Buildings by Coarse-Grid Fast Fluid Dynamics
}

\author{
Mingang Jin ${ }^{1}$, Wei Liu ${ }^{2,1}$, Qingyan Chen ${ }^{2,1^{*}}$ \\ ${ }^{1}$ School of Mechanical Engineering, Purdue University, West Lafayette, IN 47907, USA \\ ${ }^{2}$ School of Environmental Science and Engineering, Tianjin University, Tianjin 300072, China \\ *Tel. (765)496-7562, Fax (765)494-0539, Email: yanchen@purdue.edu
}

\begin{abstract}
Fast fluid dynamics (FFD) is an intermediate model between multi-zone models and computational fluid dynamics (CFD) models for indoor airflow simulations. The use of coarse grids is preferred with FFD in order to increase computing speed. However, by using a very large mesh cell to represent a heat source that could have a much smaller physical size than the cell, coarse-grid FFD would under-predict the thermal plume and thermal stratification. This investigation integrated a thermal plume model into coarse-grid FFD. The integration first used the plume model to calculate a source for the momentum equations and then corrected the temperature at the plume cell. The integration enabled coarse-grid FFD to correctly predict the plumes. When applied to displacement ventilation, coarse-grid FFD with the plume model can accurately predict the mean air temperature stratification in rooms as compared with experimental data from the literature. The improved model has also been used to calculate the ventilation rate for buoyancy-driven natural ventilation. The calculated ventilation rates agree well with the experimental data or predictions by CFD and analytical models. Coarse-grid FFD with the plume model used only a small fraction of the computing time required by fine-grid FFD, while the associated errors for the two grid sizes were comparable.
\end{abstract}

Keywords: Heat sources, plume model, computational fluid dynamics, experimental validation, analytical model 


\section{Introduction}

Whole-building airflow simulations are required in applications such as natural ventilation design, coupled building airflow and energy simulation, smoke control, and air quality diagnosis in a building. These simulations generally use multi-zone models [1]. However, the models can provide only very limited airflow information because of the assumption that a room within a building can be treated as a single homogeneous node. Computational Fluid Dynamics (CFD) models, on the other hand, can perform detailed airflow simulations, but the use of CFD for whole-building airflow simulations is too computationally expensive [2]. Between CFD models and multi-zone models, researchers have also developed intermediate models for whole-building airflow simulations. Zonal models [3] are typical intermediate models that can achieve a balance between reduced computing costs and the level of detail required in airflow simulations. Additionally, by using very coarse grids, coarse-grid CFD models [4] can provide more detailed airflow simulations at a competitive computing speed with respect to zonal models, and they are expected to replace zonal models in the future [2]. Fast Fluid dynamics (FFD), a recently developed intermediate model that can provide reliable simulations of indoor airflows at a speed that is about 15 times faster than CFD models, currently has great potential for performing whole-building airflow simulations [5, 6]. Because FFD is also a grid-based model, reducing the grid number can further enhance the computing speed of FFD simulations. Coarse-grid FFD would be an ideal tool for performing whole-building airflow simulations at a greatly reduced computing cost.

Although a coarse grid could significantly reduce the computing time of FFD simulations, it may cause problems in the representation of the boundary conditions encountered in building airflow simulations. For example, many heat sources in buildings are of small physical size, such as computers, desk lamps, occupants, etc. Using a very large mesh cell to represent a small-sized heat source would result in the prediction of lower energy intensity in the cell and smaller buoyancy forces from the heat source. Coarse-grid FFD would thus tend to under-predict the plume flow generated by the heat source and would not accurately predict buoyancy-driven ventilation and room air temperature distribution. Because buoyancy-driven ventilation is a major feature of high-performance building systems, such as displacement ventilation and buoyancy-driven natural ventilation systems, correct prediction of buoyancy-driven ventilation and room air temperature distribution is essential with coarse-grid FFD.

Thus it is necessary to improve the representation of small heat sources with large cells. In CFD models, simulations are normally performed on fine grids, which allows CFD models to avoid the aforementioned problem. Instead, to reduce the complexities of representing heat sources in simulations, it is still necssary for CFD models to apply simple heat source geometries or use replacement boundary conditions [7]. As intermediate models, zonal models also have the same problem of reprezenting heat sources as coarse-grid FFD does. Thus the approaches applied in zonal models to model thermal plumes could also be a potential solution for coarse-grid FFD. 
Extensive research has been conducted into the characteristics of thermal plumes [8]. Morton et al. [9] proposed a theoretical model to describe the physics of thermal plumes, and this model has been adapted for studying a wide variety of thermal plumes. Kofoed [10] experimentally studied thermal plumes generated by indoor heat sources in ventilated rooms and proposed a model coefficient to account for the influence of enclosing walls. Trzeciakiewicz [11] experimentally investigated the characteristics of thermal plumes in response to objects of varying shape, such as computers, desk lamps, and light bulbs. The investigation revealed that the experimentally determined model of a plume above a point heat source could be used to characterize the thermal plumes in displacement ventilation. Zukowska et al. [12] investigated the characteristics of the thermal plume generated by a sitting person using four different geometries and found that a rectangular box could correctly simulate the enthalpy flux and buoyancy flux generated by the person. Craven and Settles [13] performed a computational and experimental investigation to characterize the thermal plume from a person and concluded that the room temperature stratification had a significant effect on plume behavior. The aforementioned research into the characteristics of indoor thermal plumes has provided a wealth of information.

On the basis of these studies of thermal plume physics and analytical plume models, simple models have been developed to quantify ventilation and temperature distributions in buildings $[14,15]$. In addition, plume models have been used to improve the performance of other models for simulating buoyancy-driven airflows in buildings. Inard et al. [16] integrated a wall thermal plume model into a zonal model to improve the latter's performance in simulating the temperature distribution in a room. Musy et al. [17] integrated a plume model with a zonal model to obtain a better simulation of natural convection in a room with a radiative-convective heater. Stewart and Ren [18] used a plume model to improve the simulation accuracy of a zonal model for studying the airflow rising from a cooking plate. It has been shown that plume models effectively enhance the performance of zonal models in simulating buoyancy-driven airflows in buildings.

The integration of plume models with zonal models suggests that plume models could also be integrated with FFD for improving the performance of coarse-grid FFD simulations for room airflows driven by heat sources. This study therefore developed a method of implementing a plume model in FFD when the mesh cell is much larger than the heat source. The proposed integration method was also tested and evaluated.

\section{Research Method}

\subsection{Fast fluid dynamics}

FFD simulates an airflow by numerically solving a set of partial differential equations representing the transport phenomena in the airflow, Eq. (1)-(3), which are derived on the basis 
of the conservation of mass, momentum (Navier-Stokes equations), and scalar transport quantities (such as energy and species), respectively.

$$
\frac{\partial U_{i}}{\partial x_{i}}=0
$$

where $i$ or $j=1,2,3 ; U_{i}$ is the $i^{\text {th }}$ component of the velocity vector, $x_{i}$ the $i^{\text {th }}$ direction of coordinate, $t$ time, $p$ pressure, $\rho$ density, $v$ the kinetic viscosity, $F_{i}$ the $i^{t h}$ component of the body forces, $\phi$ the scalar variables, $\Gamma$ the transport coefficient for $\phi$, and $S$ the source term. In each time step, FFD solves this set of transport equations sequentially. To enhance computational efficiency, a time-splitting scheme [19] was applied to solve the transport equations. For example, FFD splits the scalar transport equation (3) into an advection equation (4) and a diffusion equation (5),

$$
\begin{gathered}
\frac{\phi^{(1)}-\phi^{n}}{\Delta t}=-U_{j} \frac{\partial \phi^{n}}{\partial x_{j}}, \\
\frac{\phi^{n+1}-\phi^{(1)}}{\Delta t}=\Gamma \frac{\partial^{2} \phi^{n+1}}{\partial x_{j}^{2}}+S,
\end{gathered}
$$

where $\phi^{n}$ and $\phi^{n+1}$ represent the variable at the current and next time steps, respectively, and $\phi^{(1)}$ represents the intermediate variables solved by the advection equation. The advection equation (4) is first solved with the conservative semi-Lagrangian scheme [20] to obtain the intermediate value $\phi^{(1)}$, and then FFD is implicitly solved using the diffusion equation (5) to update the scalar distribution at the next time step. To effectively resolve the coupling between the momentum equations and the continuity equation, a pressure projection [21] is performed force the velocity field to satisfy continuity.

\subsection{Integration with plume model}

As a result of natural convection, air surrounded by a heat source in a room can form a buoyancy plume. As the plume rises, it induces the surround air into the plume flow, and flow carries the heat from the heat source to the upper part of the room. To describe the features of buoyancydriven airflows, the plume flow rate $\left(V_{p}\right)$ and excess temperature $\left(\Delta T_{p}\right)$ in the plume region are usually the two most important parameters [22], and they vary with the heat generation rate, heat source geometry, heat source location, etc. When the mesh cell size used in coarse-grid FFD is 
much larger than the physical size of a heat source, the two parameters predicted by FFD may not be accurate. In order to improve the performance of coarse-grid FFD in predicting the thermal plume, this study used an analytical plume model with empirical coefficients to calculate the plume flow rate and the excess temperature in the plume region. The two calculated parameters were then integrated into FFD in order to represent the heat source.

By assuming axisymmetric temperature and velocity profiles and by using the similarity rule and constant entrainment ratio in the fully developed plume region, Eqs. (6) and (7) were developed to describe the excess temperature and plume flow rate, respectively, for a thermal plume generated by a point heat source [9].

$$
\Delta T_{p}=k_{T} P_{c}^{2 / 3}\left(\mathrm{z}+\mathrm{z}_{v}\right)^{-5 / 3}
$$

$$
V_{p}=k_{v} P_{c}^{1 / 3}\left(\mathrm{z}+\mathrm{z}_{v}\right)^{5 / 3}
$$

where $P_{c}$ is the convective heat generation rate from the heat source, $z$ the distance between a cross-section in the plume and the top surface of the heat source, $\mathrm{z}_{\mathrm{v}}$ the distance between the virtual start point of the plume and the top surface of the heat source, $k_{v}$ the flow rate coefficient, and $k_{T}$ the excess temperature coefficient, as shown in Figure 1. Although the heat sources in buildings are generally not point sources and the generated themal plumes are not always fully developed, researches found that it was possible to apply Eqs. (6) and (7) to simulate the plumes in a room with buoyancy-driven ventilation system [11]. To characterize themal plumes in buildings, empirical coefficients based on the investigation of heat sources in buildings were applied in Eqs. (6) and (7), where $\mathrm{k}_{\mathrm{v}}$ is $0.0051 \mathrm{~m}^{4 / 3} /\left(\mathrm{W}^{1 / 3} \mathrm{~s}\right)$ [10] and $\mathrm{k}_{\mathrm{T}}$ is $0.4 \mathrm{~K} \mathrm{~m}^{5 / 3} / \mathrm{W}^{2 / 3}$ [22]. Noted that the value of these two coeffients are only applicable for free plume generated by single heat source, it is necessary to adjust the coefficients accordingly for merging thermal plumes from multiple heat sources or thermal plume attached to solid wall [23].
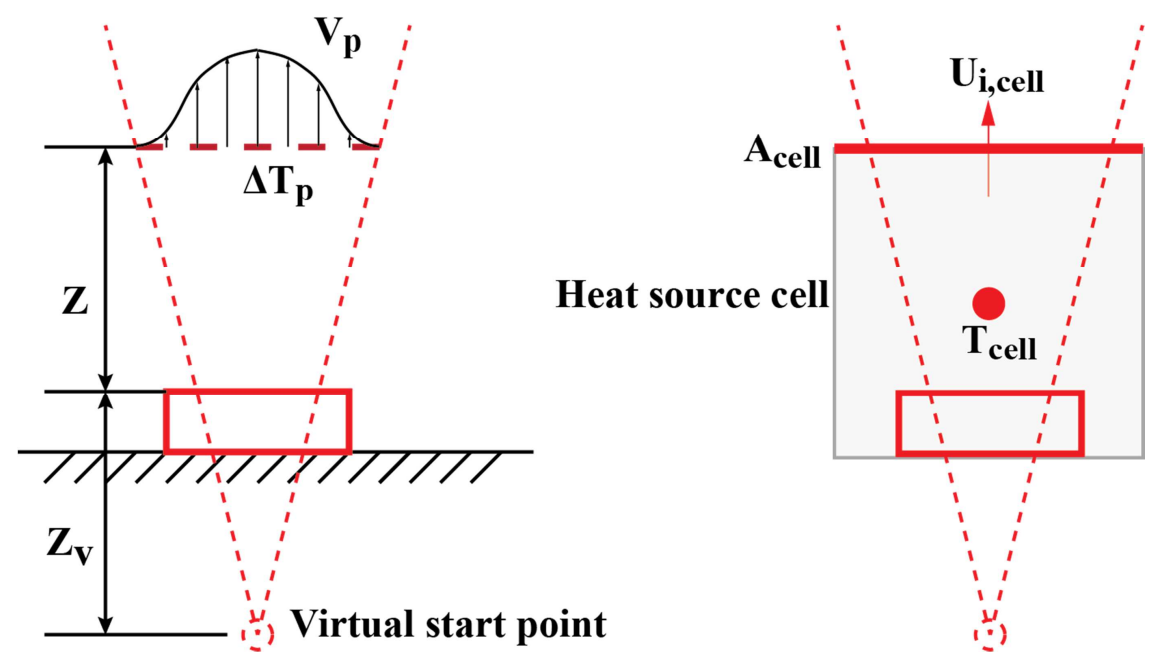

Figure 1 Schematic of the plume model and the heat source cell 
The integration of the plume model with FFD was divided into two parts: integration with the momentum equations and with the energy equation. Because coarse-grid FFD cannot correctly predict the plume flow rate driven by the heat source, Eq. (7) was used to estimate the airflow rate of the plume at the heat source cell. Dividing the flow rate by the area of the horizontal cell surface $A_{\text {cell }}$ provided an estimate of the velocity component in the plume direction $U_{i, \text { plume }}$ for the heat source cell,

$$
U_{i, \text { plume }}=V_{p} / A_{\text {cell }} \text {. }
$$

The plume velocity $U_{i, \text { plume }}$ was compared with the vertical velocity component $U_{i, \text { cell }}^{n}$ of the heat source cell at the previous time step in order to determine the amount of correction required for adjusting the velocity at the heat source cell. On the basis of the difference between $U_{i, \text { plume }}$ and $U_{i, \text { cell }}^{n}$, the momentum source or sink was calculated and was incorporated into the momentum equations as a source term, as shown in Equation (9),

$$
F_{i, \text { cell }}=F_{i, \text { cell }}+\rho\left(U_{i, \text { plume }}-U_{i, \text { cell }}^{n}\right) / \Delta t
$$

where $F_{i, \text { cell }}$ is the body force term in the heat source cell and $\Delta t$ the time step size. When the momentum source term in the cell is incorporated the plume velocity at the cell can be corrected to be the same as that in the analytical model.

For integration with the energy equation, the plume model was used to adjust the air temperature at the heat source cell because FFD underestimates the heat source temperature when a very coarse grid is used. To minimize the impact of the temperature correction on the energy conservation in the domain, the correction was applied in the advection process and before the energy conservation correction of the semi-Lagragian scheme. Therefore, a three-step approach was applied to solve the advection equation for energy transport:

$$
T_{\text {cell }}^{*}=T^{n}\left(\vec{x}_{\text {cell }}-\Delta t \vec{U}_{\text {cell }}\right),
$$

$$
T_{\text {cell }}^{* *}=T_{\text {cell }}^{*}+\left(\Delta T_{p}+T_{\text {ambient }}^{n}-T_{\text {cell }}^{n}\right)
$$

$$
T_{\text {cell }}^{(1)}=T_{\text {cell }}^{* *}+\eta_{\text {cell }} \beta
$$

where, $\vec{x}_{\text {cell }}$ represents the coordinates of the heat source cell, $\vec{U}_{\text {cell }}$ the velocity vector at the heat source cell, $\Delta t$ the time step size, $T^{n}$ the temperature at the previous time step, $T^{(1)}$ the temperature solved by the advection equation, $T_{\text {ambient }}$ the air temperature away from the plume region, $\eta$ the correction weighting factor, and $\beta$ the energy imbalance rate. To solve the advection equation for temperature at the cell, the standard semi-Lagrangian scheme was first 
191 applied to obtain intermediate temperature $T^{*}$ from Eq. (10). Next, on the basis of the excess

192 temperature calculated by the plume model, a correction was conducted for the temperature at

193 the cell in order to obtain corrected intermediate temperature $T^{* *}$ by using Eq. (11). FFD then

194 applied the energy conservation correction (Eq. (12)) to obtain the cell temperature after 195 advection.

196 When the plume model has been integrated into the momentum and energy equations according

197 to the procedure described above, FFD with coarse grids can correctly predict the airflow and

198 temperature in the heat source cell. Furthermore, the simulation is stable, and the airflow is

199 conservative.

\section{3. Results}

201 Using the integrated plume model, this study applied coarse-grid FFD to simulate building

202 airflows driven by heat sources, including displacement ventilation in a chamber with a heated

203 box, displacement ventilation in an occupied office, buoyancy-driven single-sided natural

204 ventilation, and buoyancy-driven natural ventilation in an atrium. To evaluate the performance of

205 the plume model in representing heat sources in the coarse-grid simulations, the mean vertical air

206 temperature distribution and the ventilation rate predicted by FFD with and without the plume

207 model were compared with the corresponding experimental data or analytical solution. In

208 addition, this study compared the simulation accuracy of FFD with coarse and fine grids.

\subsection{Displacement ventilation in a chamber with a heated box}

210 This study first applied FFD to simulate displacement ventilation with a single heat source and 211 compared the simulated results with the experimental data obtained by Li et al. [24]. Figure

212 2shows the test chamber with dimensions of $4.2 \mathrm{~m} \times 3.6 \mathrm{~m} \times 2.75 \mathrm{~m}$ inside a laboratory. Air at a 213 temperature of $18{ }^{\circ} \mathrm{C}$ and ventilation rate of $125 \mathrm{~m}^{3} / \mathrm{h}$ was supplied by a diffuser with dimensions 214 of $0.5 \mathrm{~m} \times 0.45 \mathrm{~m}$ located on the side wall of the test chamber at floor level. An air exhaust with 215 dimensions of $0.525 \mathrm{~m} \times 0.22 \mathrm{~m}$ was located on the front wall at ceiling level. A $300-\mathrm{W}$ cubic 216 heat source with dimensions of $0.4 \mathrm{~m} \times 0.3 \mathrm{~m} \times 0.3 \mathrm{~m}$ was placed on the floor in the center of the 217 test room. Table 1 shows the measured temperatures of the chamber's interior surfaces. 


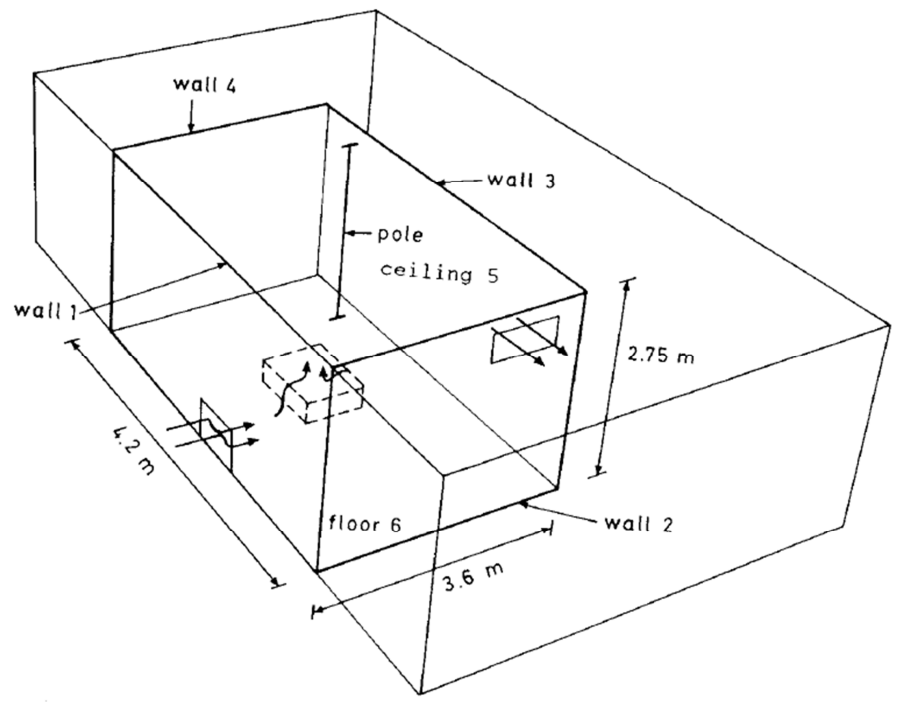

Figure 2 Geometry of the test chamber with displacement ventilation inside a laboratory [24]

Table 1 Temperatures of the chamber's interior surfaces [24]

\begin{tabular}{|c|c|c|c|c|c|c|c|}
\hline \multirow{2}{*}{ Surface } & \multirow{2}{*}{ Floor } & \multicolumn{5}{|c|}{ Side walls at different heights } & \multirow{2}{*}{ Ceiling } \\
\cline { 3 - 7 } & & $0.5 \mathrm{~m}$ & $1.0 \mathrm{~m}$ & $1.5 \mathrm{~m}$ & $2.0 \mathrm{~m}$ & $2.5 \mathrm{~m}$ & \\
\hline $\begin{array}{c}\text { Temperature } \\
(\mathrm{K})\end{array}$ & 295.1 & 295 & 295.7 & 296.5 & 296.8 & 296.8 & 298.2 \\
\hline
\end{tabular}

In the coarse-grid FFD simulations, the test chamber was represented by a total grid number of 5 $\times 5 \times 5$. Because the mesh cells were very large, the dimensions of the mesh cell containing the heat source were $0.72 \mathrm{~m} \times 0.55 \mathrm{~m} \times 0.84 \mathrm{~m}$. The cell size was almost ten times the physical size of the heat source. This study simulated the temperature distribution in the test chamber with and without the use of the plume model to represent the heat source. In addition, fine-grid FFD with a grid number of $20 \times 20 \times 20$ was applied to simulate the plume generation and temperature stratification in the test chamber.

Figure 3presents the temperature distribution and velocity field at the vertical mid-plane of the chamber as predicted by FFD with and without the plume model. Without the plume model, as shown in Figure 3(b), FFD predicted a smaller thermal plume. This is because the large cell used for the heat source would have a lower mean air temperature than that in the actual plume. Because of the reduced air temperature, the plume flow rate was also lower, and there was less air entrainment from the surroundings. However, with the plume model as depicted in Figure 3(a), the predicted air entrainment was much greater. Because the energy intensity was reduced in the large heat source cell, FFD without the plume model predicted an unrealistically low air temperature in the plume region, as illustrated by Figure 3b). For example, the air temperature in the plume region was even lower than that at ceiling level. The model correctly predicted the 
high air temperature near the ceiling that was caused by the rising thermal plume, as shown in 242 Figure 3(a).

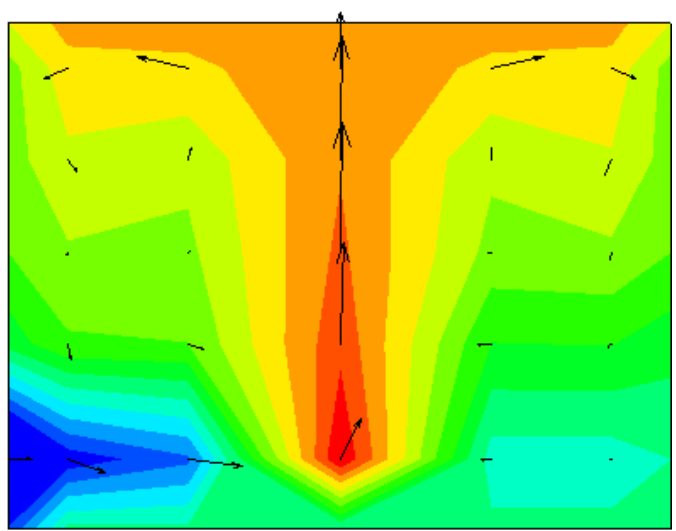

(a)

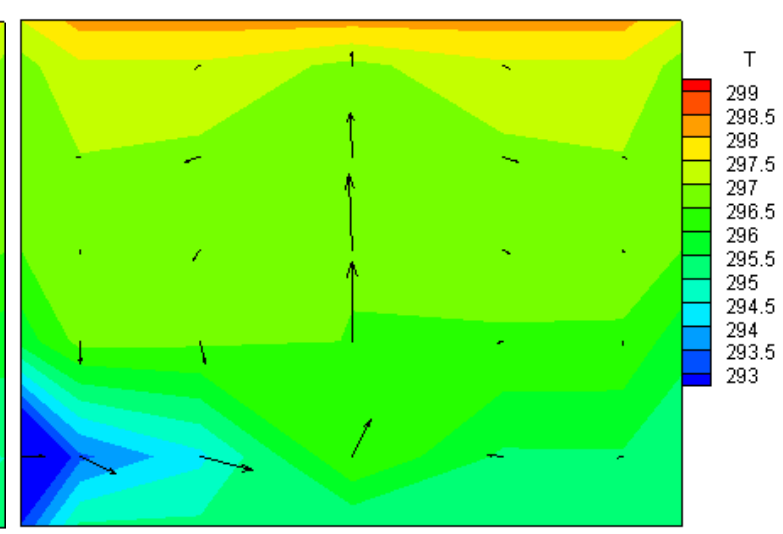

(b)

Figure 3 The air temperature and velocity distribution at the vertical mid-plane of the test chamber as predicted by FFD (a) with the plume model and (b) without the plume model

This study further examined the mean air temperature distribution at different heights in the test chamber as predicted by coarse-grid FFD. Figure 4 compares the temperature profile predicted by course-grid FFD with those from fine-grid FFD and the data measured by Li et al. [24]. FFD without the plume model under-predicted the temperature stratification in the chamber, and it predicted temperatures that were too low in the upper part of the chamber and too high at floor level. Coarse-grid FFD with the plume model produced a temperature profile that agrees much better with the experimental data, except in the region near the floor. Because the temperature gradient near the floor was high, the grid resolution used by coarse-grid FFD was too low to accurately reflect the large temperature variation in this region. Fine-grid FFD provided a slightly better prediction of the temperature profile near the floor. Due to the averaging of the temperature at the same hight, the discrepency between the temperature profiles predicted by two models was not as apprant as observed in Figure 3. But it was still obvious that the plume model improved FFD's prediction of thermal plume [24]. Coarse-grid FFD with the plume model was able to simulate the temperature stratification with an acceptable accuracy for engineering applications. 


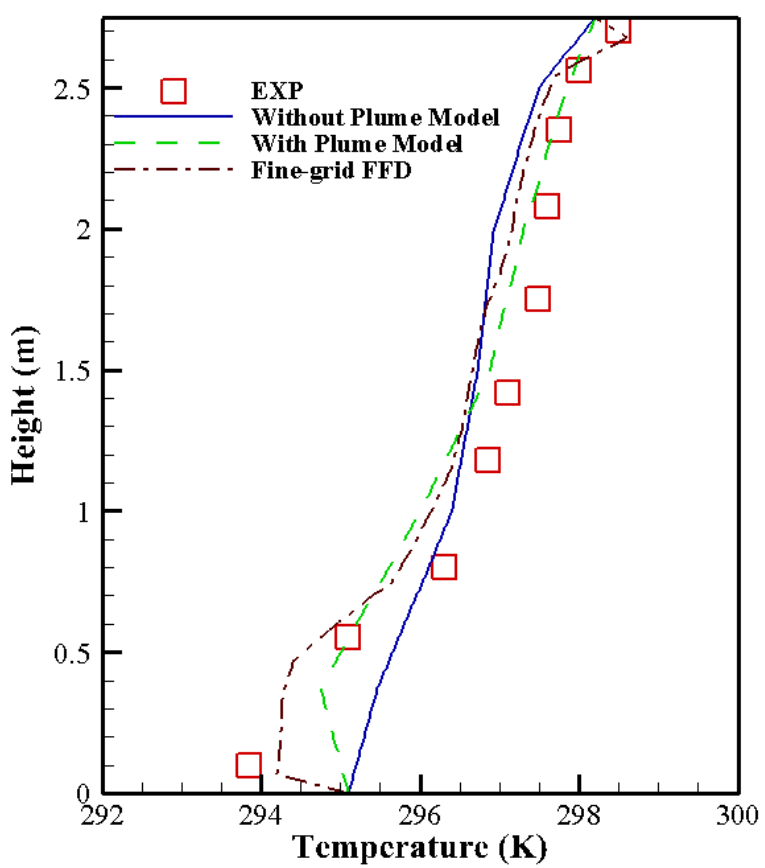

264 Figure 4 Comparison of the mean vertical air temperature profiles in the chamber as predicted by coarse-grid FFD with and without the plume model and by fine-grid FFD, as well as the measured profile.

\subsection{Displacement ventilation in an occupied office}

269 To evaluate the performance of the plume model for improving the accuracy of coarse-grid FFD 270 in simulating thermal plumes, this study next investigated airflows in an occupied office space 271 with displacement ventilation. An office mock-up with dimensions of $5.16 \mathrm{~m} \times 3.65 \mathrm{~m} \times 2.43 \mathrm{~m}$ 272 was used by Yuan et al. [25] for experimental measurements, as shown in Figure 5(a). Air at a 273 temperature of $17.0{ }^{\circ} \mathrm{C}$ was supplied through a displacement diffuser on the side wall at floor 274 level at a ventilation rate of $183.1 \mathrm{~m}^{3} / \mathrm{h}$. The air was exhausted through an outlet located in the 275 center of the ceiling. Two heated dummies with dimensions of $0.4 \mathrm{~m} \times 0.4 \mathrm{~m} \times 0.7 \mathrm{~m}$ to simulate 276 occupants, and two heated boxes with dimensions of $0.4 \mathrm{~m} \times 0.4 \mathrm{~m} \times 0.4 \mathrm{~m}$ to simulate computers, were placed in the chamber as heat sources. These heat sources generated thermal plumes that reached the upper part of the room. The experiment by Yuan et al. [25] measured the air temperature along nine vertical poles distributed in the streamwise center plane (P1-P5) and the cross-sectional center plane (P6-P9), as shown in Figure 5(b). 


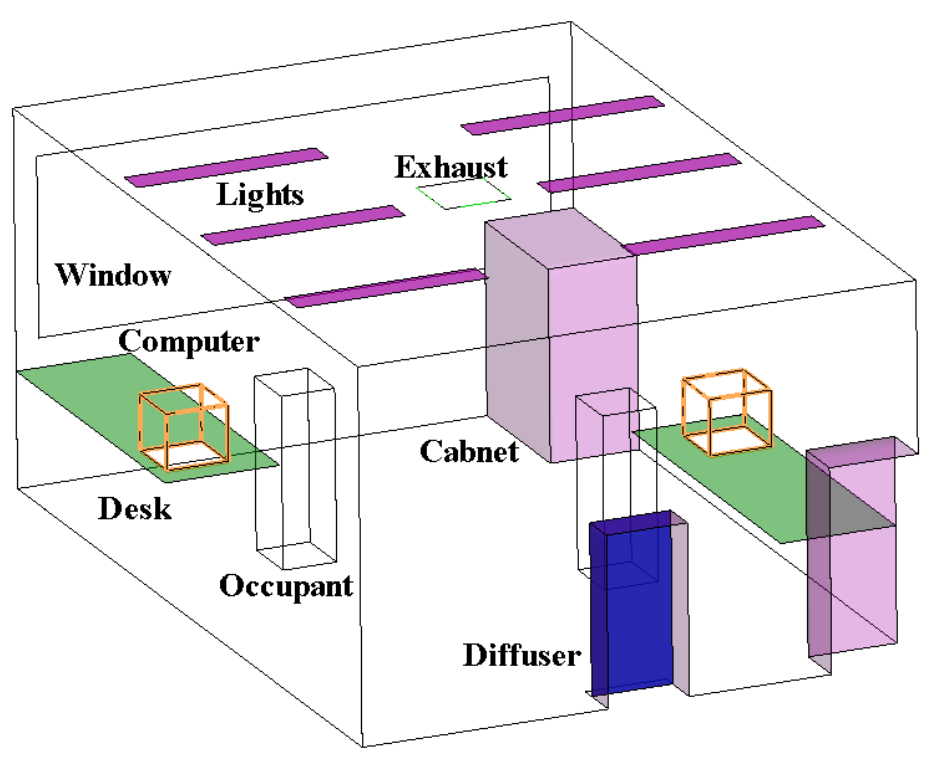

(a)

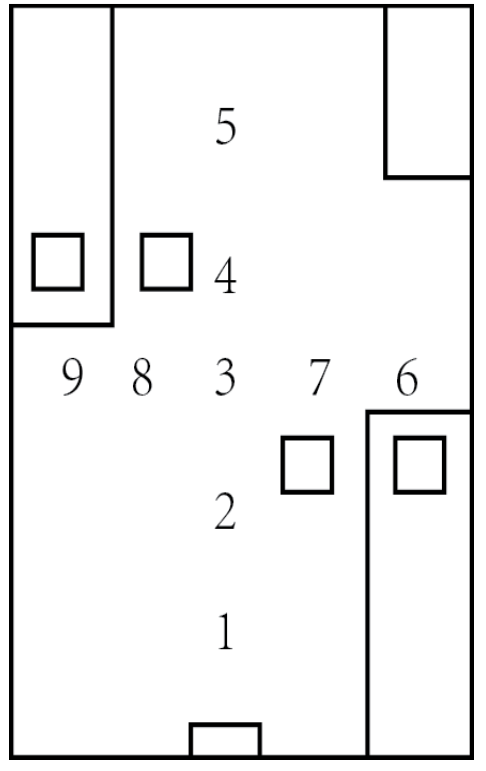

(b)

Figure 5 (a) Schematic of the office with displacement ventilation and (b) the measurement locations

The coarse-grid FFD simulations used $5 \times 5 \times 8$ mesh cells to represent the office, as shown in Figure 6. Since the mesh was very coarse, two of the cells contained heat sources, and each contained an occupant and a nearby computer on a desk. Each heat source cell had dimensions of $0.7 \mathrm{~m} \times 0.75 \mathrm{~m} \times 0.75 \mathrm{~m}$. Once again, the simulations were performed by coarse-grid FFD with and without the plume model and by fine-grid FFD with a cell number of $20 \times 20 \times 20$.

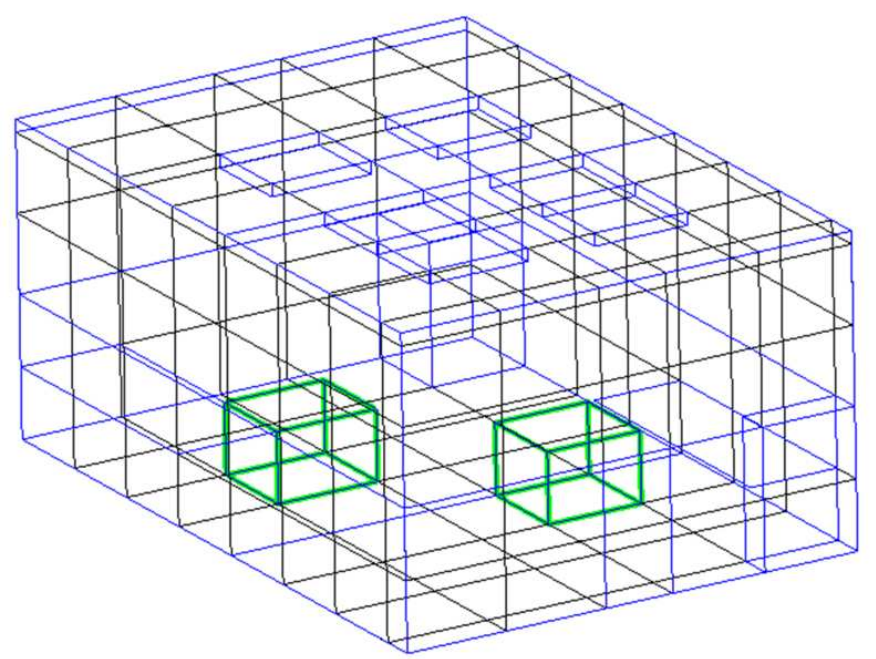

Figure 6 Coarse grid used to represent an office with two heat sources 
294 Figure 7 compares the vertical air temperature distribution at five locations (PI-P5) predicted by 295 coarse-grid and fine-grid FFD with the experimental data. The results at the other measured 296 locations (P6-P9) were similar, but they are not presented here because of the limited space 297 available in this paper. Coarse-grid FFD without the plume model could not correctly predict the 298 air temperature profiles as compared with the experimental data. Because the thermal plumes 299 were artificially weakened by the use of a large cell to represent the heat sources, the amount of 300 energy transported to the upper part of the room was significantly reduced. Thus, in the upper 301 part of the office the predicted air temperature was lower than that measured experimentally. 302 However, the use of the plume model to represent heat sources improved the accuracy of the 303 coarse-grid FFD in simulating the buoyancy flows driven by the heat sources and thus provided a 304 better prediction of the vertical air temperature profiles. In addition, the simulation results proved 305 the viability of combining several adjacent heat sources into a single heat source so that the 306 plume model could be used. Interestingly, coarse-grid FFD can predict the air temperature 307 profiles with accuracy similar to that of fine-grid FFD. 

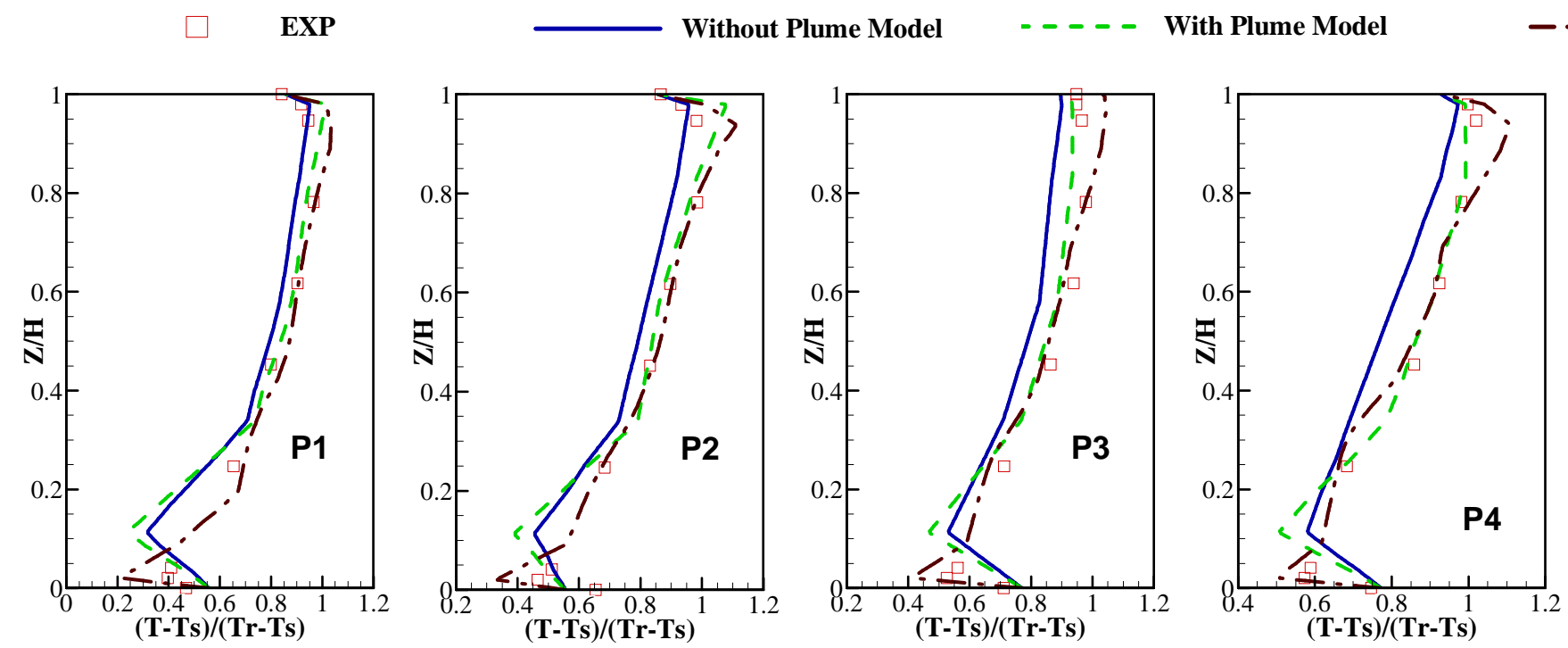

- $-\cdots$ Fine-grid FFD

Figure 7 Comparison of the vertical air temperature profiles at five positions (P1-P5) as predicted by various FFD models and according to experimental data from Yuan et al. [25] 


\subsection{Buoyancy-driven single-sided natural ventilation}

310 Following the successes in the displacement ventilation cases, this study applied the coarse-grid 311 FFD to more challenging cases, such as buoyancy-driven natural ventilation, where flow rate is 312 determined by thermal plumes. The case selected for buoyancy-driven natural ventilation in this study was taken from Jiang and Chen [26], who used a test chamber with dimensions of $5.34 \mathrm{~m}$ $\times 3.57 \mathrm{~m} \times 2.46 \mathrm{~m}$ inside a laboratory to simulate the indoor environment, and the surrounding laboratory space to simulate the outdoor environment, as shown in Figure 8(a). The thermal plume was generated by a 1500-W baseboard heater with dimensions of $0.16 \mathrm{~m} \times 0.2 \mathrm{~m} \times 0.7 \mathrm{~m}$ that was placed on the floor in close proximity to the interior wall. An open door was used to simulate the single-sided opening where natural ventilation occurred. Because the walls of the test chamber and environmental chamber were of very high insulation value, they were considered to be adiabatic. Jiang and Chen measured the vertical air temperature profiles at five different locations, as shown in Figure 8(b), as well as the ventilation rates in the test chamber. Table 2 shows the enclosure surface temperatures of the laboratory as measured by Jiang and Chen.

Table 2 Enclosure surface temperatures of the laboratory

\begin{tabular}{|l|l|l|l|l|l|l|}
\hline & Ceiling & Floor & North wall & South wall & East wall & West wall \\
\hline Temperature $(\mathrm{K})$ & 296.11 & 295.11 & 296.01 & 295.90 & 293.94 & 295.83 \\
\hline
\end{tabular}

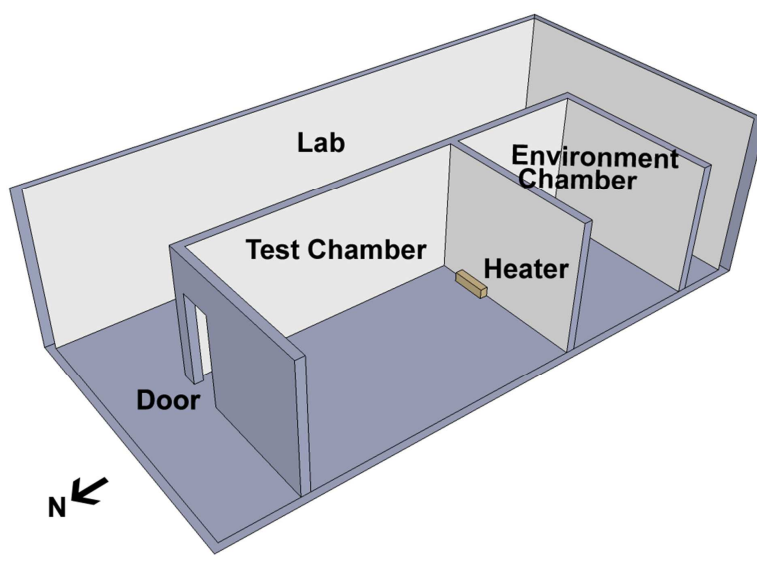

(a)

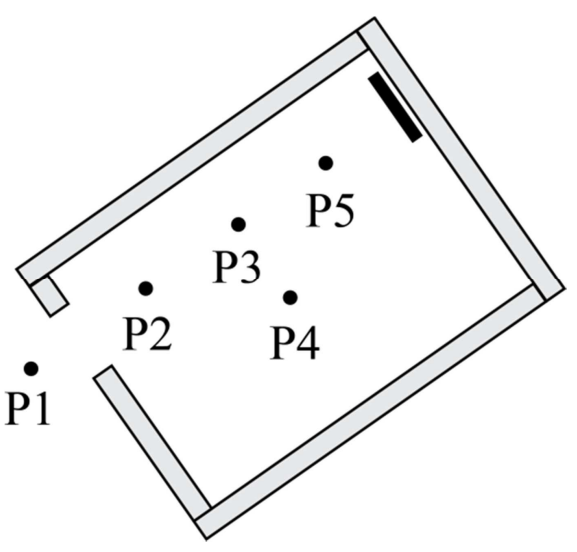

(b)

Figure 8 (a) Sketch of experimental setup and (b) measurement positions inside and outside the test chamber 
Our coarse-grid FFD used $18 \times 10 \times 10$ mesh cells to represent the entire laboratory, while $6 \times 6$ $\times 6$ cells were used for the test chamber, and a single cell of $0.3 \mathrm{~m} \times 0.64 \mathrm{~m} \times 0.7 \mathrm{~m}$ was used for the baseboard heater. Note that the latter cell was much larger than the physical size of the heater. In addition, the entire laboratory in this case was simulated by FFD with a fine grid of 30 $\times 20 \times 20$.

Figure 9 compares the vertical air temperature profiles simulated by coarse-grid FFD with and without the plume model and by fine-grid FFD, with the experimental data at positions P1, P2, P3, and P5. The temperature profiles predicted by coarse-grid FFD with the plume model and by fine-grid FFD were in very good agreement with the measured profiles. Coarse-grid FFD without the plume model resulted in temperature profiles that did not agree as well with the experimental data. The model predicted a lower air temperature in the upper part of the room because of the weaker-than-actual thermal plume predicted by the cell that was much larger than the heater.

Because the buoyancy flow generated by the heater was the primary driving force for the airflow in the chamber, correct simulation of the thermal plume was crucial for the prediction of the ventilation rate through the door opening. Table 3 compares the ventilation rates computed by coarse-grid FFD with and without the plume model and by fine-grid FFD, with the experimental data. Some uncertainties were observed in the measured data for this case. They resulted from instabilities in the natural ventilation system, which caused the ventilation rate to vary from 9.18 to $12.6 \mathrm{ACH}$. Because of the reduced heat source intensity in the large heat source cell, a small plume was predicted by the coarse-grid FFD without the plume model. As a result, the predicted ventilation rate was low in comparison with the lowest measured ventilation rate. Both the coarse-grid FFD with the plume model and the fine-grid FFD can accurately predict the ventilation rate caused by the thermal plume from the heater in the chamber. Coarse-grid FFD with the plume model predicted a ventilation rate that was equal to the mean value in the experiment.

Table 3 Ventilation rates for the buoyancy-driven, single-side natural ventilation case obtained from various models and the experiment by Jiang and Chen [26].

\begin{tabular}{|c|c|c|c|c|}
\hline & & & \multicolumn{2}{|c|}{ Coarse-grid FFD } \\
\cline { 4 - 5 } & Experiment & Fine-grid FFD & $\begin{array}{c}\text { Without plume } \\
\text { model }\end{array}$ & $\begin{array}{c}\text { With plume } \\
\text { model }\end{array}$ \\
\hline $\begin{array}{c}\text { Ventilation rate } \\
(\mathrm{ACH})\end{array}$ & $9.18-12.6$ & 9.36 & 7.4 & 10.6 \\
\hline
\end{tabular}



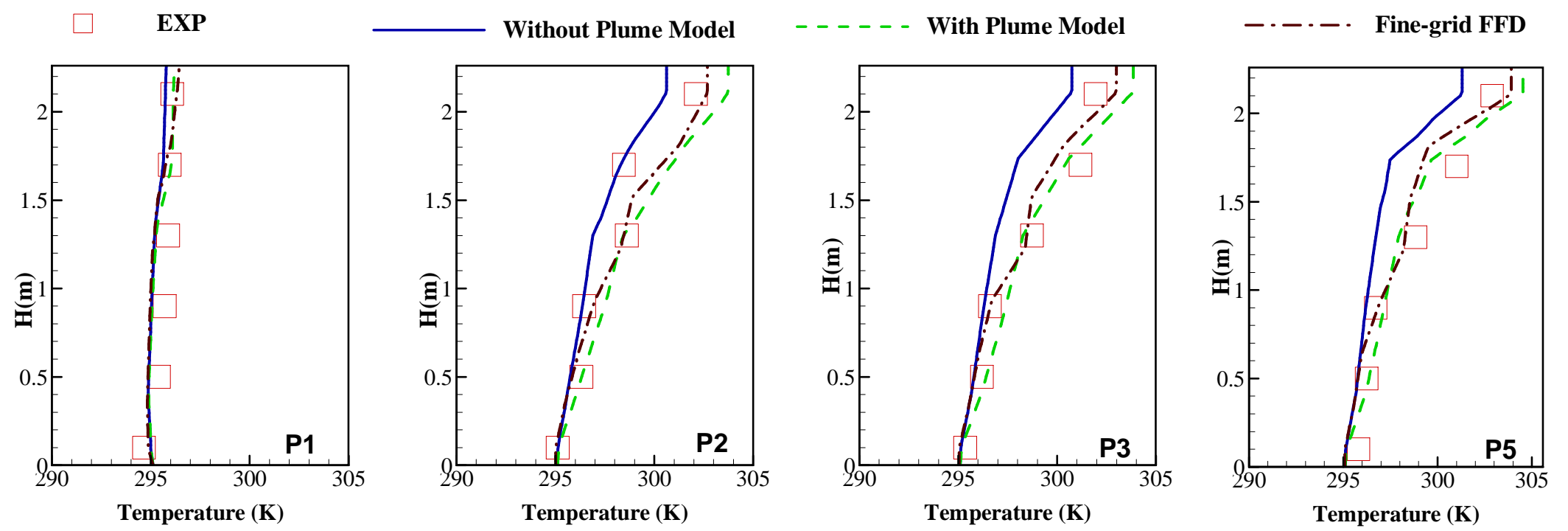

Figure 9 Comparison of the vertical air temperature profiles predicted by various FFD models with the experimental data from Jiang and Chen [26]. 
361 This study also applied FFD to the simulation of buoyancy-driven natural ventilation in an 362 atrium, which is a major feature of modern natural ventilation designs for buildings. A tool that 363 predicts the ventilation rate of buoyancy-driven airflow through an atrium with reasonable 364 accuracy would effectively help architects improve natural ventilation designs. To test the 365 performance of coarse-grid FFD in simulating atrium-assisted natural ventilation, this study 366 simulated buoyancy-driven natural ventilation flows in a single-storey space connected to an 367 atrium [27].

368 Figure 10 shows a case in which a scaled building shell of $2.5 \mathrm{~m}(\mathrm{~W}) \times 6.5 \mathrm{~m}(\mathrm{~L}) \times 1.58 \mathrm{~m}(\mathrm{H})$ 369 was connected to an atrium with a height of $3.71 \mathrm{~m}(\mathrm{M})$. A heat source of $100 \mathrm{~W}$ was placed in 370 the center of the building to generate a buoyancy force. The building was ventilated through a 371 top-down chimney (TDC) located near the left wall. An opening was constructed in the ceiling of 372 the building shell connected to the atrium so that air could travel between the building and the 373 atrium. Because of the thermal plume generated by the heat source, ambient air flowed through 374 the TDC to the floor of the building and was entrained by the thermal plume. The plume 375 transported the air to ceiling level, and then the air travelled towards the atrium. Finally, the air 376 flowed outside through the outlet in the ceiling of the atrium. The ventilation rate would vary 377 with the area of the opening $\left(\mathrm{A}_{\mathrm{u}}\right)$. With a constant effective single-storey opening area of 0.044 $378 \mathrm{~m}^{2}$ [27], this study varied the area of the atrium outlet in order to examine the performance of 379 coarse-grid FFD in simulating the natural ventilation rate $\left(\mathrm{Q}_{\mathrm{v}}\right)$. A grid size of $13 \times 8 \times 5$ was 380 used for the entire building. 


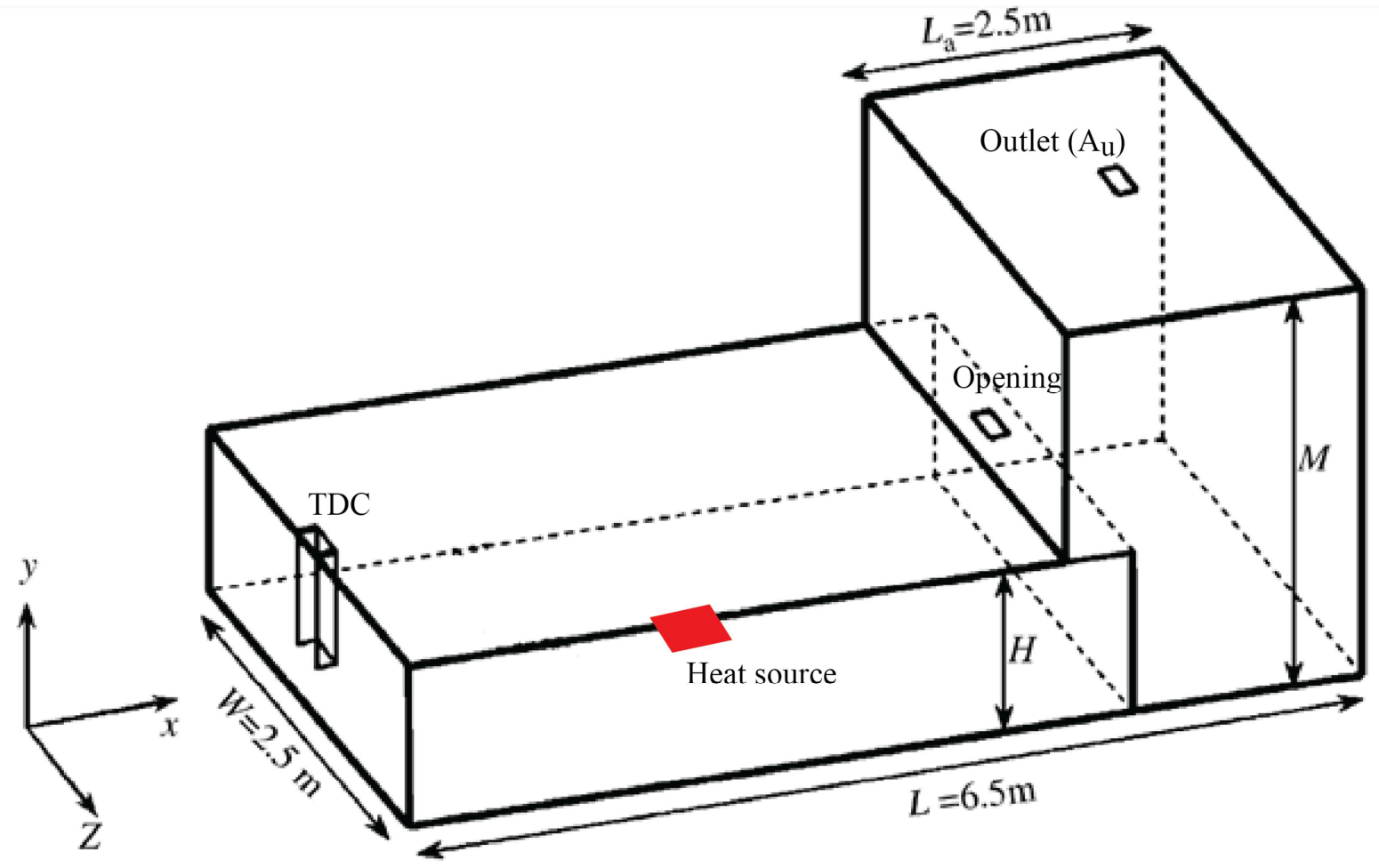

Figure 10 Geometry and opening locations of the scaled building with an atrium [27]

Figure 11 shows the relationship between the ventilation rate and the atrium outlet size as predicted by coarse-grid FFD with and without the plume model. Results obtained by CFD [27] and an analytical model [15] are also shown for the purpose of comparison. The analytical model was developed from experimental data that should be quite reliable. The ventilation rate $\left(\mathrm{Q}_{\mathrm{v}}\right)$ was normalized by the volume flow rate $\left(\mathrm{Q}_{\mathrm{H}}\right)$ of a pure thermal plume at ceiling height, and the atrium outlet size $\left(\mathrm{A}_{\mathrm{u}}\right)$ was normalized by the squared height $\left(\mathrm{H}^{2}\right)$ of the building. As the size of the atrium outlet increased, the natural ventilation rate also increased. For coarse-grid FFD without the plume model, the predicted ventilation rate was significantly lower than that calculated by the analytical model. Because the heat source was represented by a very large cell, the predicted temperature at the heat source cell were likely to have been much lower, and the buoyancy force much smaller, than they would be in reality. As a result, coarse-grid FFD without the plume model could not predict the natural ventilation rate well. Coarse-grid FFD with the plume model was able to predict a flow rate that was close to that predicted by CFD. The FFDpredicted ventilation rate also agreed with that from the analytical model. Therefore, the plume model can effectively improve the accuracy of coarse-grid FFD for simulating buoyancy-driven natural ventilation. 


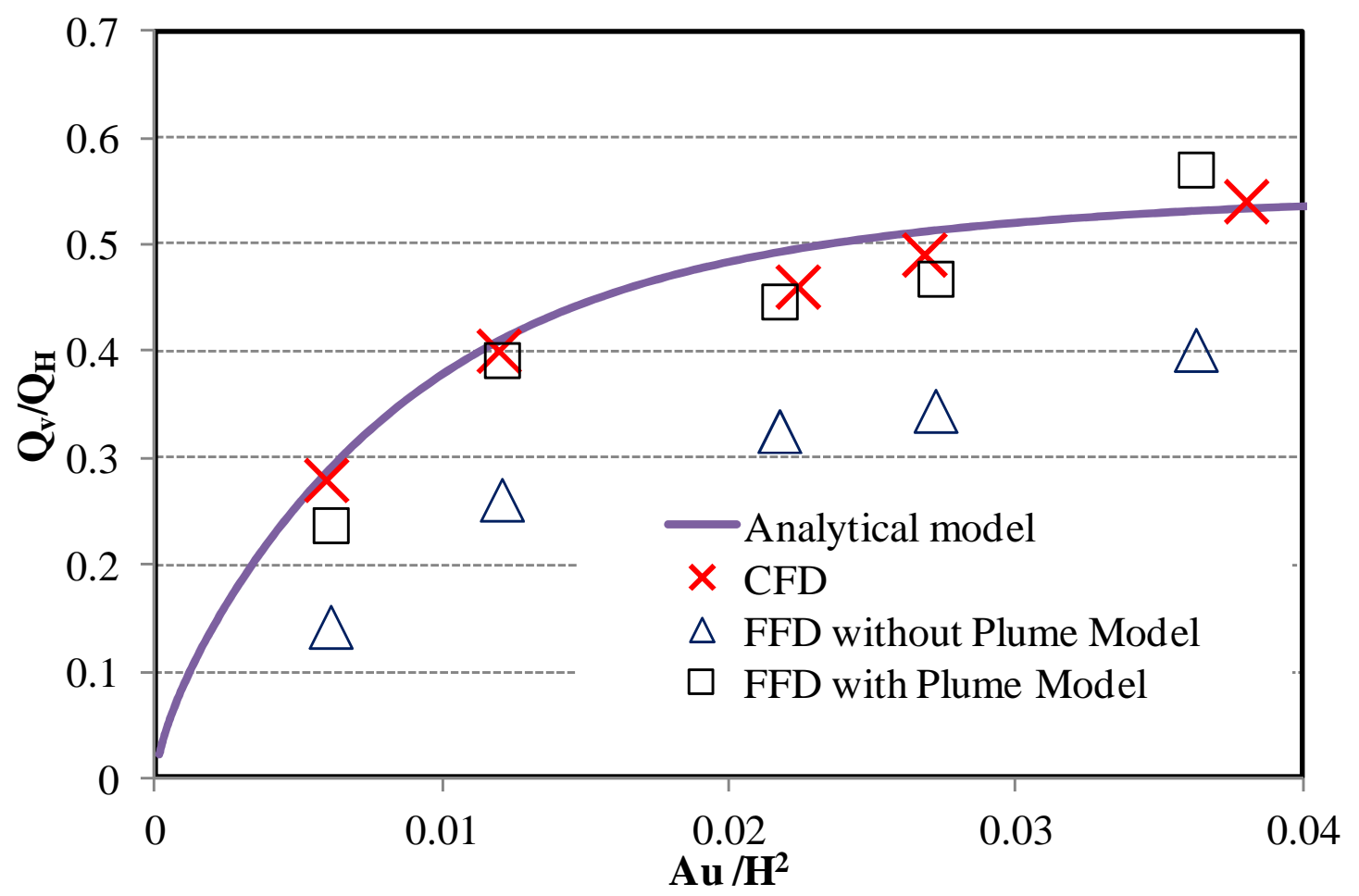

Figure 11 Variation in ventilation rate with outlet size for the scale building with an atrium as predicted by different models

\section{Discussion}

The tests described above demonstrated that the effectivness of the plume model. It helps coarsegrid FFD achieve better performance for simulating temperature stratification in rooms with buoyancy-driven ventilation and ventilation rate for buoyancy-driven natural ventilation. Through tuning the model coefficients for individual cases, it is possible to further improve the simulation results, as the development of thermal plume is different from case to case. However, because the purpose of FFD is not to obtain as accurate simulation as CFD does, the investigation on the impact of coefficients on improving the accuracy of coarse-grid FFD is limited in this study.

To examine the overall benefits of the plume model for FFD simulations, this study further investigated the computing time and accuracy of coarse-grid FFD with and without the plume model and fine-grid FFD for predicting temperature distributions. The computing time was recorded for each model by using the elapsed time when running the simulation for 1000 time steps. In addition, the root mean square errors based on the differences between the simulated 
results and the experimental data were used to quantify the accuracy. The computing time and errors in each case were normalized with those of the fine-grid FFD.

Table 4 shows that the coarse grid could significantly reduce computing time, by 5 to 50 times according to the coarseness of the grid. On the other hand, the coarse grid produced slightly large errors, but they do not seem to be critical for our applications. In a decision as to whether or not to use FFD, computing time is a much more critical factor than computing accuracy. Coarse-grid FFD with the plume model had errors that were similar to those of fine-grid FFD. Without the plume model, the errors could be quite large, as shown in Table 4.

Table 4 Comparison of computing time and simulation error with the use of different FFD models

\begin{tabular}{|c|c|c|c|c|}
\hline \multirow{3}{*}{ Case } & Model & $\begin{array}{c}\text { Grid number } \\
(\mathrm{X} \times \mathrm{Y} \times \mathrm{Z})\end{array}$ & $\begin{array}{c}\text { Normalized } \\
\text { computing } \\
\text { time }\end{array}$ & $\begin{array}{c}\text { Normalized } \\
\text { error }\end{array}$ \\
\hline \multirow{3}{*}{1} & Fine-grid FFD & $20 \times 20 \times 20$ & 1 & 1 \\
\cline { 2 - 5 } & Coarse-grid FFD w/o plume model & $5 \times 5 \times 5$ & 0.019 & 2.43 \\
\cline { 2 - 5 } & Coarse-grid FFD w/ plume model & $5 \times 5 \times 5$ & 0.019 & 1.67 \\
\hline \multirow{3}{*}{2} & Fine-grid FFD & $25 \times 18 \times 16$ & 1 & 1 \\
\cline { 2 - 5 } & Coarse- grid FFD w/o plume model & $5 \times 5 \times 8$ & 0.032 & 1.44 \\
\cline { 2 - 5 } & Coarse-grid FFD w/ plume model & $5 \times 5 \times 8$ & 0.033 & 1.03 \\
\hline \multirow{3}{*}{3} & Fine-grid FFD & $30 \times 20 \times 20$ & 1 & 1 \\
\cline { 2 - 5 } & Coarse- grid FFD w/o plume model & $18 \times 10 \times 10$ & 0.226 & 3.03 \\
\cline { 2 - 5 } & Coarse-grid FFD w/ plume model & $18 \times 10 \times 10$ & 0.226 & 1.46 \\
\hline
\end{tabular}

\section{Conclusions}

This study proposed the integration of a thermal plume model into coarse-grid FFD in order to more accurately simulate airflows driven by thermal plumes. The integration used the plume flow rate calculated by the plume model to estimate the source for the momentum equations in FFD. The integration also used the plume model to predict the air temperature at the heat source cell for correcting the prediction by the energy equation in FFD.

This study applied coarse-grid FFD with the plume model to simulate airflows in buildings driven by thermal buoyancy forces. Displacement ventilation and buoyancy-driven natural ventilation cases were used. Experimental data and CFD results from the literature were used to compare with the predicted results by the integrated FFD model. Coarse-grid FFD with the plume model greatly improved FFD performance in predicting air velocity and temperature in the plume, which led to a more accurate prediction of mean air temperature stratification in the displacement ventilation cases. The results were comparable to those of fine-grid FFD. 
Coarse-grid FFD with the plume model was also able to accurately predict the ventilation rate in buoyancy-driven natural ventilation cases. The accuracy was comparable to that of fine-grid FFD, CFD, or an analytical model developed from experimental data.

The computing time for coarse-grid FFD with and without the plume model was a small fraction of that for fine-grid FFD for all the cases tested. The coarse-grid number was actually the minimum necessary for representing room air distribution. At the same time, the significant reduction in grid number did not lead to a much larger error than that of fine-grid FFD, especially for coarse-grid FFD with the plume model.

\section{Acknowledgement}

This research was funded partially by the Energy Efficient Building Hub led by the Pennsylvania State University through a grant from the U.S. Department of Energy and other government agencies, where Purdue University was a subcontractor to the grant.

\section{References}

[1] Axley J. Multizone airflow modeling in buildings: History and theory. HVAC\&R Research. 2007;13:907-28.

[2] Chen Q. Ventilation performance prediction for buildings: A method overview and recent applications. Building and Environment. 2009;44:848-58.

[3] Megri AC, Haghighat F. Zonal modeling for simulating indoor environment of buildings: Review, recent developments, and applications. HVAC\&R Research. 2007;13:887-905.

[4] Wang H, Zhai Z. Application of coarse-grid computational fluid dynamics on indoor environment modeling: Optimizing the trade-off between grid resolution and simulation accuracy. HVAC\&R Research. 2012;18:915-33.

[5] Jin M, Zuo W, Chen Q. Improvements of fast fluid dynamics for simulating air flow in buildings. Numer Heat Transfer, Part B: Fundamentals. 2012;62:419-38.

[6] Jin M, Zuo W, Chen Q. Simulating natural ventilation in and around buildings by fast fluid dynamics. Numerical Heat Transfer, Part A: Applications. 2013;64:273-89.

[7] Zelensky P, Bartak M and Hensen J. Simplified representation of indoor heat soruces in CFD simulations. Proceedings of 13th Conference of International Building Performance Simulation Association, Chambéry, France, August 26-28, 2013.

[8] Carazzo G, Kaminski E, Tait S. On the rise of turbulent plumes: Quantitative effects of variable entrainment for submarine hydrothermal vents, terrestrial and extra terrestrial explosive volcanism. Journal of Geophysical Research: Solid Earth (1978-2012). 2008;113. 
[9] Morton B, Taylor G, Turner J. Turbulent gravitational convection from maintained and instantaneous sources. Proceedings of the Royal Society of London, Series A: Mathematical and Physical Sciences. 1956;234:1-23.

[10] Kofoed P. Thermal Plumes in Ventilated Rooms: Aalborg Universitetsforlag; 1991.

[11] Trzeciakiewicz Z. An experimental analysis of the two-zone airflow pattern formed in a room with displacement ventilation. International Journal of Ventilation. 2008;7:221-31.

[12] Zukowska D, Melikov A, Popiolek Z. Thermal plume above a simulated sitting person with different complexity of body geometry. Proceedings of the 10th International Conference on Air Distribution in Rooms-Roomvent. 2007; 191-198.

[13] Craven BA, Settles GS. A computational and experimental investigation of the human thermal plume. Journal of Fluids Engineering. 2006;128:1251-8.

[14] Linden PF. The fluid mechanics of natural ventilation. Annual Review of Fluid Mechanics. 1999;31:201-38.

[15] Holford JM, Hunt GR. Fundamental atrium design for natural ventilation. Building and Environment. 2003;38:409-26.

[16] Inard C, Bouia H, Dalicieux P. Prediction of air temperature distribution in buildings with a zonal model. Energy and Buildings. 1996;24:125-32.

[17] Musy M, Wurtz E, Winkelmann F, Allard F. Generation of a zonal model to simulate natural convection in a room with a radiative/convective heater. Building and Environment. 2001;36:589-96.

[18] Stewart J, Ren Z. Prediction of indoor gaseous pollutant dispersion by nesting sub-zones within a multizone model. Building and Environment. 2003;38:635-43.

[19] Ferziger JH, Perić M. Computational Methods for Fluid Dynamics. New York: Springer; 1999.

[20] Jin M, Chen Q. Improvement of Fast Fluid Dynamics with a Conservative Semi-Lagrangian Scheme. International Journal of Numerical Methods for Heat and Fluid Flow. 2015; 1.

[21] Chorin AJ. A numerical method for solving incompressible viscous flow problems. Journal of Computational Physics. 1967;2:12-26.

[22] Bouzinaoui A, Devienne R, Fontaine JR. An experimental study of the thermal plume developed above a finite cylindrical heat source to validate the point source model. Experimental Thermal and Fluid Science. 2007;31:649-59.

[23] Kofoed P, Nielsen P. Thermal Plumes in ventilated rooms - Vertical Vlume Flux Influenced by Enclosing Walls. The 12th AIVC-Conference.1991.

[24] Li Y, Sandberg M, Fuchs L. Vertical temperature profiles in rooms ventilated by displacement: Full-scale measurement and nodal modelling. Indoor Air. 1992;2:225-43. 
512 [25] Yuan X, Chen Q, Glicksman L, Hu Y, Yang X. Measurements and computations of room 513 airflow with displacement ventilation. ASHRAE Transactions. 1999;105:340-52.

514 [26] Jiang Y, Chen Q. Buoyancy-driven single-sided natural ventilation in buildings with large 515 openings. International Journal of Heat and Mass Transfer. 2003;46:973-88.

516 [27] Ji Y, Cook M, Hanby V. CFD modelling of natural displacement ventilation in an enclosure 517 connected to an atrium. Building and Environment. 2007;42:1158-72. 